\title{
ADAPTIVE IMAGE ENHANCEMENT AND ATMOSPHERIC CORRECTION FOR CARTOSAT-2S
}

\author{
Ms. Dikshita Bagde \\ M-Tech $2^{\text {nd }}$ Year, \\ Department of CSE \\ G H Raisoni College \\ of Engineering, Nagpur, \\ Maharashtra, India
}

\author{
Dr. Pradeep Kumar \\ Associate Professor, \\ Department of CSE \\ G H Raisoni College \\ of Engineering, Nagpur, \\ Maharashtra, India
}

\author{
Dr. Mani Kumar Vedantam \\ Data Pre-processing and \\ Network Application Division, \\ Software Group/DPPA \& WAA, \\ NRSC, ISRO Hyderabad.
}

Mr. Devi Vara Prasad

Division Head, Sci/Engr. - 'SF', Sci/Engr. - 'SD'

Earth climate science area, Shadnagar, NRSC

ISRO, Hyderabad.
Abstract - Atmospheric correction (Removing Atmospheric Effects from satellite imagery) is for urban cities where haze is prominent. Better retrieval of water constituent parameters of lakes (lake retreat) - site selection - city water bodies, coastal changes, estuary changes - for water atmospheric correction plays very important role. For better atmospherically correction we need to Rayleigh correction, Aerosol Correction, other gases correction (O3 and $\mathrm{H} 20$ (water vapour)) using existing climatological or other satellite data in near real time mode. Enhancement of data can be improved after performing above corrections and also using histogram analysis.

Keywords- Atmospheric correction, cloud-snow-fog detection, image enhancement, water bodies analysis.

\section{INTRODUCTION}

Magnetic force energy flows probably equally from the rays of the sun through the atmosphere, and after that straight to that same sensing part. Absorption decreases the energy pressure which is mirrored. Emitting redirects EM resources into the environment and causes located near damage wherever the square weighs opposing pixels are exchanged. Such two methods, the principal catalyst for image representation, affect a picture's consistency and area structure. In order to describe the surface reflectivity (surface properties), atmospheric adjustment eliminates the scattering and absorption effects from the atmosphere.

The non-particular emission (source of light) released into the environment at sun light spectrum from a surface water, or groundwater-leaving brightening, transformed by the sunlight underside radiometric case, distinguishes the reflectivity of "remote sensing" and water reflectivity from the angular problem of AN.

Sea body applies to oceans, seas, streams, reservoirs, forests, channels, and smaller water bodies, as even the aquatic reflectivity nomenclature is widely used for ocean and coastal waters.

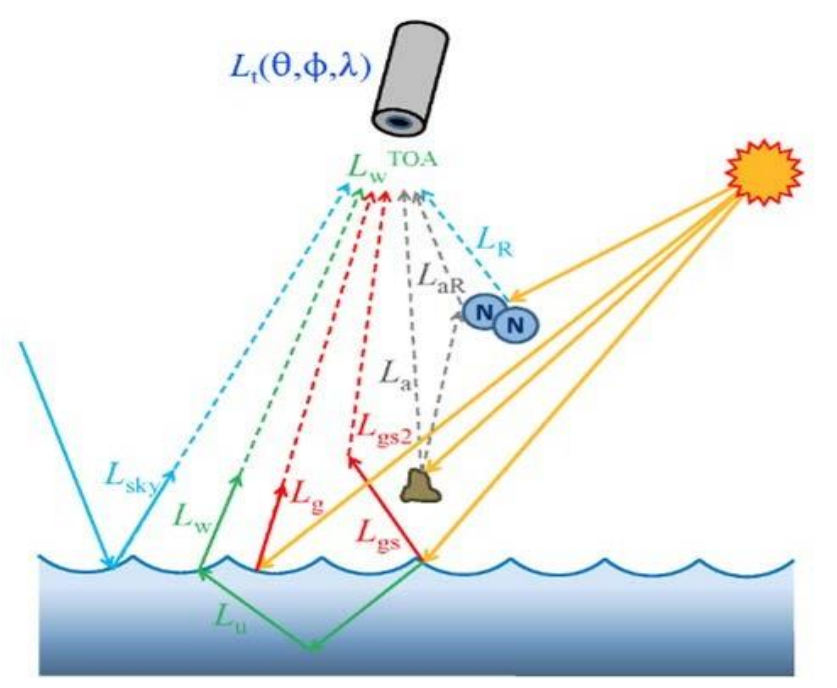

Formula:

$\operatorname{Lt}(\mathrm{x})=\operatorname{LR}(\mathrm{x})+[\operatorname{La}(\mathrm{x})+\operatorname{LaR}(\mathrm{x})]+\mathrm{TLg}(\mathrm{x})+\operatorname{tLwc}(\mathrm{x})+$ $\operatorname{tLw}(\mathrm{x})$

Here,

LR (x) - Rayleigh radiance

La (x) - aerosol radiance

LaR (x) - interaction term between aerosol and molecular scattering

Lg (x) - glint radiance

Lwc (x) - whitecap radiance

Lw (x) - water leaving radiance

$\mathrm{t}$ - Rayleigh-aerosol diffuse transmittance

$\mathrm{T}$ - Direct transmittance

Cloud droplet reflection makes it challenging to detect the ground area snowy conditions (the fog reflection is basically dominant), except when particles are visible light thin or cover a small portion of the ground, i.e. their ground wavelength effect is less than 0.2 .

The signal of interest (usually contains information about water constituents) must be excluded from the radar data in order to give access to clean absorption coefficient, the influence of environment and ground. This is commonly 
called atmospheric correction, although the process involves the removal of surface effects. Exhaust gases accumulation is easy to manage while the spacecraft device detects in ambient shutters (the normal position), but difficult to correct when observations are taken in the sequestering frequency band (e.g., hyper-spectral detectors measured in the electromagnetic spectrum), where cellular diffraction pattern can be reliably calculated.

Atmospheric correction might be essential to calculate biogeochemical properties sponsored reflective surface coefficient until it eliminates attenuation effects induced by active atmospheric components such as molecular and aerosol dispersion and absorption by water, ozone, $\mathrm{O}$ and carbon dioxide. In addition the right elimination of ambient influences is optimal for water surfaces due to the weak reflection coefficient. The surface coefficient of reflection quality is extremely enthusiastic about the methodology of atmospheric correction, the atmospheric-surface properties

\section{METHODOLOGY}

\section{A. Algorithm -}

Satellite image enhancement alters the currently trendy visual impact that the image has on the interpreter which improves the quality of knowledge. Satellite image enhancement techniques include contrast enhancement, IHS transformation (Intensity, Hue, and Saturation), density slicing, edge enhancement, digital mosaics, and synthetic stereo images.

Data collection of satellite imagery used in visual enhancement creation. Satellite image enhancement is the most widely needed technique in the field of satellite image processing to enhance feature visualization. Image enhancement methodology produces high quality picture.

After enhancement of images classification occur like land, snow, cloud, desert, etc. Features detection and extraction apply on different classification. At this spatial resolution, the adaptive modeling approach blends satellite data to produce synthetic daily seeming reflectance.

Modelling approaches square measure ideal once scene specific atmospherically information (aerosol content, vapour, gasified surroundings, etc.) square measure accessible. However, atmospherical data is never accessible. Therefore, in our case we've got designed the potential of correcting the pictures.

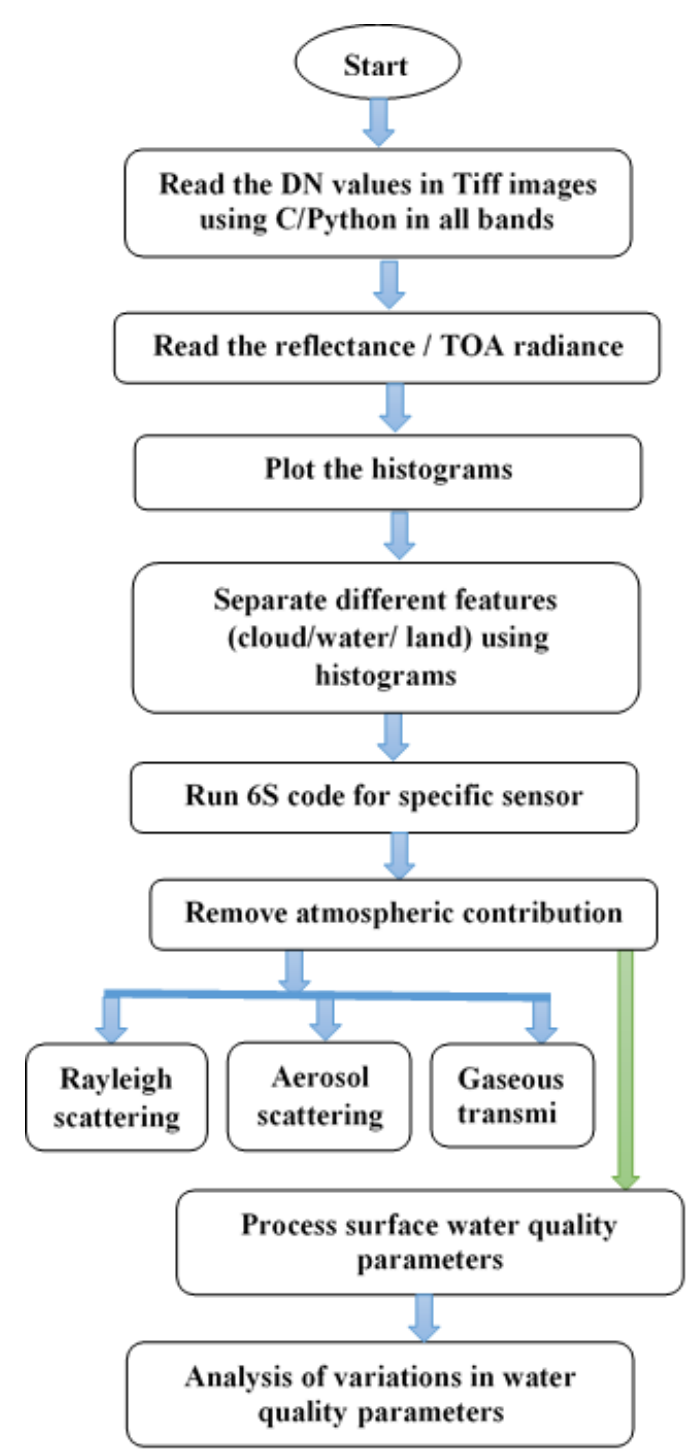

Fig. Flow diagram of atmospheric correction process

\section{B. Cartosat Series -}

The picture that is submitted by satellite square unit planning to be useful for application development. In addition to geographical details, Agricultural and non - agricultural requirements, piece of land use and the control of coastal regions, supply chain management such as road network monitoring, water supply, resource utilization dashboard development, geographical classification change and manmade alternatives and varied alternative land details system(LIS) in addition as Geographical data System (GIS) applications. 
International Journal of Engineering Applied Sciences and Technology, 2020

Vol. 5, Issue 2, ISSN No. 2455-2143, Pages 333-336

Published Online June 2020 in IJEAST (http://www.ijeast.com)

\section{B. TABLE 1-}

\begin{tabular}{|l|l|}
\hline \multicolumn{1}{|c|}{ Satellite } & $\begin{array}{l}\text { CARTOSAT } \\
\text { (Cartosat 2series) }\end{array}$ \\
\hline Launch date & 12 Jan 2018 \\
\hline \multicolumn{1}{|c|}{ Bands } & $\begin{array}{r}\text { PAN } \\
\text { P.45 - } 0.90) \\
(0.43-0.52) \\
(0.52-0.61) \\
(0.61-0.69)\end{array}$ \\
& $\begin{array}{r}\text { PAN- } 0.65 \\
\text { HRMX-2 }\end{array}$ \\
\hline Resolution & 505 \\
\hline Altitude (km) & 7 \\
\hline Revisit time (days) & 10 \\
\hline Swath & 11 bit \\
\hline Quantization bit & \\
\hline
\end{tabular}

\section{IMPLEMENTATION AND RESULTS}

Developed methodology tested on various data sets of Cartosat-2S. One result of Cartosat-2F is presented here to showcase the capability of developed software. After atmospheric correction, the dark targets appear to be darker and bright targets much brighter. increased for atmospherically corrected image.

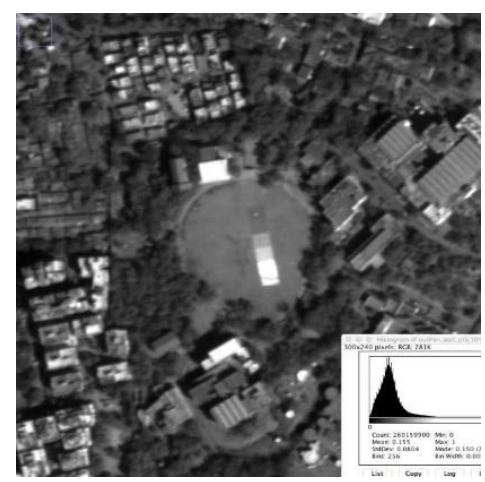

Fig. Cartosat-2F, 15 Feb 2018, PAN top of the atmosphere (left)

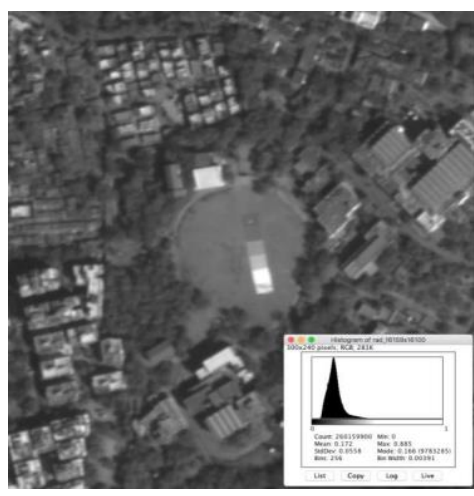

Fig. Cartosat-2F, 15 Feb 2018, Ground reflectance (right) image.

This is an indication that effect of aerosol scattering and absorption has been compensated. Dynamic range has also

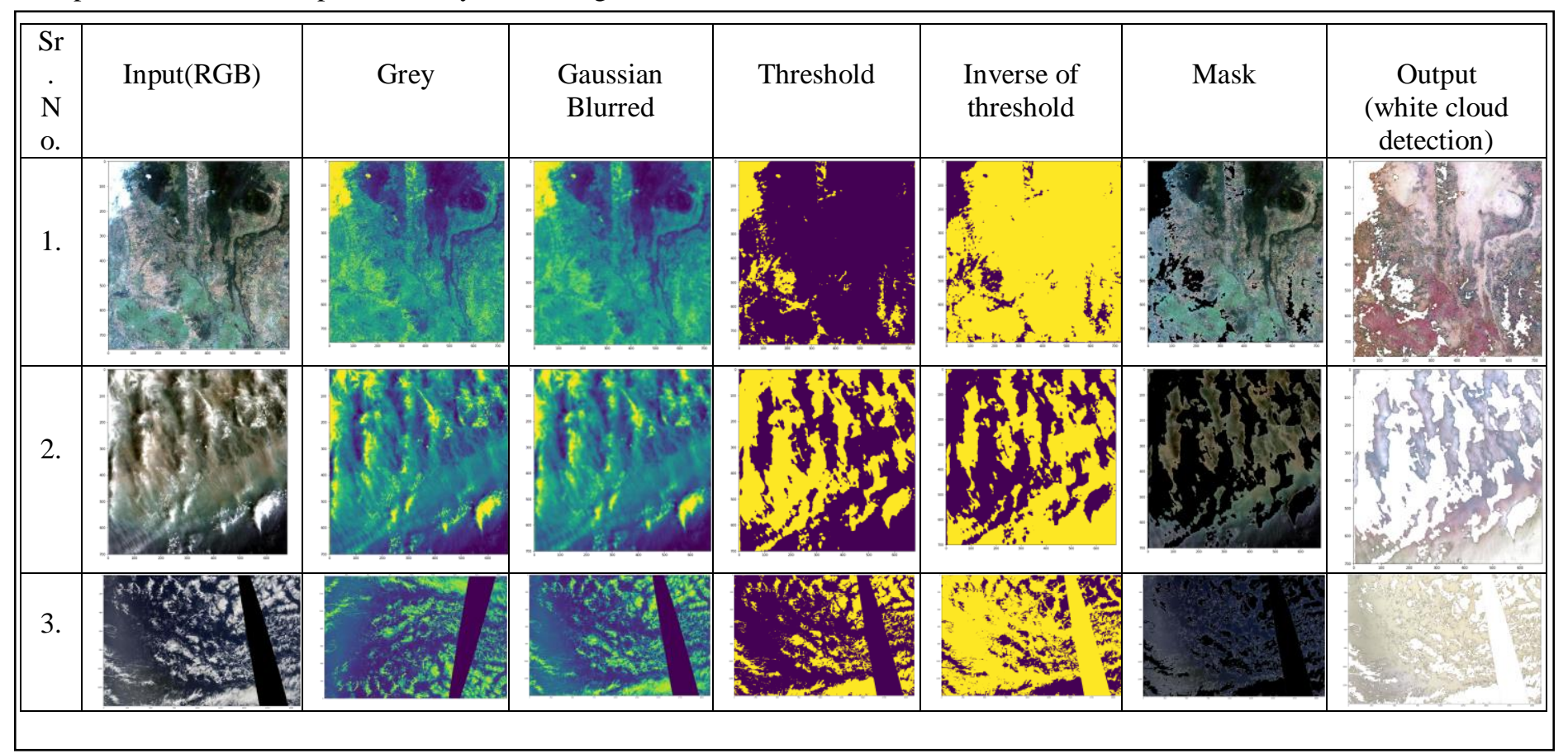




\section{CONCLUSION}

For obvious reasons, there must be a growing interest in assessing the performance of different climatic clarification on fresh and marine lakes and rivers: individuals are with our whole main current part of the hydrological cycle, they are extensively used by recreation and naturally contain natural resources (marine and freshwater solar energy); This paper deals with eliminating environmental impacts from Landsat images for improved analysis of water parameters.

Urban surface water mapping is currently important for learning the role it plays in urban ecosystems and native microclimates. Nevertheless, quick and accurate urban water extraction remains a strong challenge due to the limitations of traditional water indexes and also the existence of atmospheric impacts.

Satellite imaging can be useful for geographic information system objectives, industrial and rural uses, agricultural land use and regulation, traffic management, such as path mapping, river transport, land use review, geographical and manmade change recognition, and many other Ground Information System and Geographic Information System. This needs at least two pairs of images as the inputs into the algorithm. Then render three stages of variants to determine the exact response.

\section{ACKNOWLEDGEMENT:}

The study is under the auspices of Hyderabad City's accessible Key Cloud Detection Project, edge enhancement, and image recognition. Meanwhile, the National Remote Sensing area of India and the graduate studies Innovation platform as well as doctoral students encourage this research. The writers wish to thank Scientist for kindly supplying the data analysis source code. The authors hereby accept and thank Anonymous Researcher for his positive feedback for supplying the satellite data used in the analysis.

\section{REFERENCE}

[1] Bhavani I.V.G., Rao T. D. V. P, Das A., Choudhury S.B., Nagamani P. V., Prasad K. V. S. R., Sasmal S. K. (2018). Impact of ozone concentration on ocean color retrievals for OCM-2. IPSR- International Archives of the Photogrammetry, Remote Sensing and spatial Information Sciences, 2018.

[2] Jensen J.R. (2000). Remote Sensing of the Environment: An Earth Resource Perspective. 2nd Ed. Prentice-Hall, Inc.; Upper Saddle River, NJ: 2000. p. 544.

[3] Vermote E.F., Tanré D., Deuzé J.L., Herman M. and Morcrette J.-J. (1997). Second Simulation of the Satellite Signal in the Solar Spectrum, 6S: An
Overview, IEEE Transactions on Geoscience and Remote Sensing, Vol. 35, No. 3, p. 675-686.

[4] Wilson R.T. (2012). Py6S: A Python interface to the 6S Radiative Transfer Model; Geography and Environment, University of Southampton, High field Campus, Southampton, SO17 1BJ, UK.

[5] Frouin, R.J., Franz B.A., Ibrahim A., K., Knobelspiesse Z. Ahmad, Cairns B., Chowdhary J., Dierssen H.M., Tan J., Dubovik O., Huang X., Davis A.B., Kalashnikova O., Thompson D.R., Remer L.A., Boss E., Coddington O., Deschamps P.-Y., Gao B.C., Gross L., Hasekamp O., Omar A., Pelletier B., Ramon D., Steinmetz F., and Zhai P.-W. (2019). Atmospheric correction of satellite ocean-color imagery during the PACE Era. Front. Earth Sci., 7, 145.

[6] Frouin Ed R. (2013). (Dartmouth, NS: IOCCG). "Inflight calibration of satellite ocean-color sensors," Report No. 14 of the International Ocean-Color Coordinating Group, IOCCG 2013. Pp. 106.

[7] Pereira-Sandoval M., Ruescas A., Urrego P., A. Ruiz-Verdú, Delegido J., Tenjo C., Soria-Perpinyà X., Vicente E., Soria J. and Moreno J. (2019). Evaluation of Atmospheric Correction Algorithms over Spanish Inland Waters for Sentinel-2 Multi Spectral Imagery Data, Article.

[8] Gao B.C., Montes M. J., Davis C.O., Goetz A.F.H. (2009). Atmospheric correction algorithms for hyper spectral remote sensing data of land and ocean. Remote Sensing Environment. p. S17-S24.

[9] Wang M. (ed.), (2010). International Ocean Colour Cooperating Group (IOCCG). Atmospheric Correction for Remotely-Sensed Ocean-Colour Products; International Ocean Colour Cooperating Group (IOCCG): Cape Town, South Africa.

[10] Wu W., Li Q., Zhang Y., Du X. and Wang H. (2018). Two-Step Urban Water Index (TSUWI): A New Technique for High-Resolution Mapping of Urban Surface Water: Article, Remote Sensing.

[11] Mahavir (2000). High (Spatial) Resolution vs. Low Resolution Images: A Planner's View Point. International Archives of Photogrammetry and Remote Sensing. Vol. XXXIII, Supplement B7. Amsterdam 2000.

[12] Mishra K., Prasad P. R. C. (2015). Automatic Extraction of Water Bodies from Landsat Imagery Using Perceptron Model. Hindawi Publishing Corporation Journal of Computational Environmental Sciences Volume 2015, Article ID 903465, 9 pages.

[13] Syrris V., Ferri S., Ehrlich D., and Pesaresi M. (2015). Image Enhancement and Feature Extraction Based on Low-Resolution Satellite Data. IEEE Journal of Selected Topics in Applied Earth Observations and Remote Sensing, Vol. 8, No. 5. 